LAW, ETHICS AND MEDICINE

\title{
Treating competent patients by force: the limits and lessons of Israel's Patient's Rights Act
}

\section{L Gross}

J Med Ethics 2005;31:29-34. doi: 10.1136/jme.2002.000877

Competent patients who refuse life saving medical treatment present a dilemma for healthcare professionals. On one hand, respect for autonomy and liberty demand that physicians respect a patient's decision to refuse treatment. However, it is often apparent that such patients are not fully competent. They may not adequately comprehend the benefits of medical care, be overly anxious about pain, or discount the value of their future state of health. Although most bioethicists are convinced that partial autonomy or marginal competence of this kind demands the same respect as full autonomy, Israeli legislators created a mechanism to allow ethics committees to override patients' informed refusal and treat them against their will. To do so, three conditions must be satisfied: physicians must make every effort to ensure the patient understands the risks of non-treatment, the treatment physicians propose must offer a realistic chance of significant improvement, and there are reasonable expectations that the patient will consent retroactively. Although not all of these conditions are equally cogent, they offer a way forward to assure care for certain classes of competent patients without abandoning the principle of autonomy altogether. These concerns reach past Israel and should engage healthcare professionals wary that respect for autonomy may sometimes cause avoidable harm.

Correspondence to: Dr M L Gross, Department of Political Science, University of Haifa, Israel; mgross@poli.haifa.ac.il

Received 23 June 2002 In revised form 4 October 2002 Accepted for publication 28 February 2003
$\mathrm{T}$ he decision to treat any patient by force is wrenching. Largely limited to incompetent patients, there are very few instances where one might imagine treating a competent person in defiance of his or her express wishes. In fact, the moral principle of respect for autonomy, together with statutes protecting patient rights, expressly forbids coerced treatment. Yet in the spirit of a communitarian democratic state that deliberately blurs the lines between public and private spheres of interest and unabashedly interferes in the latter, Israeli law makers codified a wide range of fundamental patient rights while providing for a mechanism to violate them at the same time.

In many respects, the Israel Patient's Rights Act (IPRA) of $1996^{1}$ differs little from policy and practice in other nations. Patients enjoy a wide the right of informed consent, privacy, confidentially, and respect for dignity. Meaningful range of rights including national healthcare, informed consent enjoins healthcare professionals to provide a wealth of information about risks, benefits, and alternative treatments. Had Israeli legislators stopped here, patients rights would suffer no less than they do elsewhere as healthcare professionals struggle to implement the law in the face of the day to day constraints inherent in an overtaxed public healthcare system. But Israeli policy moves one step further by allowing physicians to override the right of informed consent and to forcibly treat competent patients against their will when they feel certain that their patients are making the wrong decision about their medical care.

The simple issue of a patient's best interest, very often lost in the rhetoric surrounding "respect for autonomy" but the lynchpin of paternalistic medical practice, was clearly on the minds of Israeli lawmakers. In most instances, competent patients gladly accept medical treatment. In many remaining cases physicians will relent when a patient balks, usually because the treatment they propose does not offer significant benefits over the alternative the patient prefers. In rare cases, however, there are serious differences of opinion when the patient refuses clearly beneficial treatment and, despite every reasonable effort, continues to reject appropriate care. In those cases one could well imagine physicians simply wanting to tie down their patients and treat them anyway. Well, the Israeli law allows just that. When this law first appeared I examined some of the philosophical difficulties associated with Israeli medical paternalism. ${ }^{2}$ Now, several years later, I want to note some of the practical implications and lessons that emerge as we try to implement the law's provisions.

\section{FORCIBLY TREATING COMPETENT PATIENTS: THE RIGHT AND OBLIGATION TO COERCE}

The dilemma posed by non-consensual treatment is not new. Although courts in the United States and in the UK have supported a physician's duty to treat incompetent patients against their express wishes, jurists have balked when asked to impose treatment on competent, adult patients. In exceptional cases, however, the courts permitted non-consensual treatment for the protection of third parties, usually fetuses or minor children. In those cases where patients appeared competent and no third party interests were at stake, it was necessary to establish that either a patient was temporarily impaired or unduly coerced or influenced at the time he or she made a decision to refuse treatment. This 
supports the underlying theme in Western bioethics: namely, that a competent, adult patient can refuse treatment even at risk to themselves. ${ }^{34}$

In Israel, however, the legal and medical community have taken a much different stance and, in stark contrast to the British and American cases just described, allow a patient's best interest to supercede his choice of care. This can only be justified, as Englehardt suggests, in a community, "where individuals have already agreed to a particular ordering of goods and harms that will place successful medical intervention higher than liberty interests" ${ }^{4}$ Indeed, Israel is such a community.

Although democratic nations adhere closely to a trinity of rights that protect a person's life, liberty, and dignity, a liberal conception of justice, as such, does little to tell us how to rank these norms. In many Western nations, for example, there is a clear preference for dignity and liberty over life: acutely ill patients command the right to die with dignity and without state interference, hunger striking prisoners are left to die of starvation rather than endure force feeding, while heinous criminals may face execution but never cruel or unusual punishment. Israeli democratic norms, on the other hand, diverge dramatically on these issues. The state can interfere with a patient's very limited right to die and keep a patient alive against his will, hunger strikers may be force fed, ${ }^{5}$ and while criminals (specifically, suspected terrorists) may endure "moderate physical pressure" during interrogation they will never face execution. In these cases the state exercises its duty to protect life at the expense of liberty and dignity.

With this duty in mind, the IPRA establishes statutory ethics committees to consider a physician's request to forcibly treat a competent patient who refuses medical care (physicians who wish to withhold medical information from competent patients for therapeutics reasons (therapeutic privilege) must also obtain permission from the ethics committee). Committee members include two physicians from different specialties, an attorney fit to serve as district court judge, a representative of the public or clergy, and a psychologist or social worker (IPRA, paragraph 24). Ethics committees sitting in the court's stead as they consider forced treatment may draw on the opinions of local and district courts, and issue rulings that are legally binding. To this end, they are bound by certain conditions that raise problems themselves.

\section{FORCIBLY TREATING COMPETENT PATIENTS: THREE CONDITIONS}

The IPRA stipulates three conditions before a patient can be forcibly treated (paragraph 15.2). Firstly, a physician must ascertain that her patient receives the information necessary to make an informed choice. Secondly, treatment must "significantly improve" a patient's condition. Finally, there must be reasonable grounds to suppose that, after receiving treatment, the patient will give "retroactive consent". Although each of these conditions exhibits certain logic, a number of difficulties arise in practice.

\section{Condition 1: informed consent}

The largest single obstacle to forced treatment is the doctrine of informed consent or more precisely, "informed refusal". Although there are instances where competent patients may be treated without informed consent (in the emergency room

In two landmark American cases involving Jehovah's Witnesses, higher courts overruled lower courts that had permitted physicians to treat a patient against her wishes (Application of the President and Directors of Georgetown College, 331 F.2d 1000 (D.C. Cir), certiorari denied, 377 US 978, 1964; In re Brooks, 205 NE 2d 435 (III SC 1965)). for example), one cannot conceive of any justification for treating any patient who competently refuses treatment. Informed refusal hinges upon the same conditions as informed consent and requires: "informability" (the patient's capacity to receive, recognise, remember, and comprehend information), cognitive and affective capabilities (the capacity to relate situations to oneself, and reason about and rank alternatives), choice (the capacity to select an option and resign oneself to that choice), and defensibility (the capacity to recount, explain, and defend one's decision). ${ }^{\circ}$

In acute settings, however, it is often difficult to obtain fully informed consent making it important to designate lesser, acceptable states of decision making capacity. White, for example, distinguishes between "marginally competent" and "adequately competent" patients, the former requiring "the assistance of others to reach a decision," so that "given time and assistance, they can usually reach (or agree with) a decision". ${ }^{6}$ Thewes et al describe common examples of decision making capacity "confounded" by shortsightedness (a tendency to overemphasise present health care states and discount future states), invulnerability ("it can't happen to me"), fear of pain, and "atypical" values (Jehovah's Witness for example). ${ }^{7}$ Cassell et al measured diminished levels of cognitive functioning among sick patients that appear to account for their shortsightedness and illogical thinking. ${ }^{8}$ Nevertheless, in nearly all of these instances (as far as many bioethicists interpret them) patients retain decision making capacity and their decisions-including refusals-demand respect. ${ }^{79}$ In Israel the situation is quite the opposite, for the law intends to override patient autonomy precisely when patients deemed competent refuse life saving treatment. ${ }^{10}$

Although sweeping grounds for violating informed consent run counter to the tenor of Western bioethics, I would like to try to defend it on more narrow grounds and in a way consistent with the way Israelis order their basic democratic values. As noted above, there are several categories of marginal competence that reflect disagreements between patients and physicians. On closer examination, it is apparent that these disagreements turn on either disputed facts or disputed values. When patients refuse medical treatment because they do not fully understand the risks of nontreatment, overestimate pain, or ignore (or discount) pertinent information, then their disagreements with caregivers turn on disputed facts. Once the factual issue is resolved, a reasonably intelligent patient will usually adopt the course of treatment his physician proposes.

Although disputed facts often explain many refusals to accept treatment, a number of others hinge on conflicting values. A patient may well understand the issues at stake and prefer alternative treatment or no treatment at all. Although treatment may extend a patient's life, the costs in terms of curtailed lifestyle, for example, may lead a patient to prefer a shorter life under some conditions rather than a longer life under others. This is the common defense for autonomy and respect for a patient's decision to forego treatment. This argument, however, which commonly respects disparate values, fails to account for factual disagreements. Refusals stemming from disputed facts and refusals stemming from disparate values do not command equal respect.

The distinction between disagreements of fact and value is pivotal for any attempt to justify treating a competent patient by force. Misinformation and misunderstanding underlie disagreements of fact and a cardinal condition of informed consent rests precisely on competently processed information. As a result, a patient's refusal to assent to treatment because facts are incompletely grasped is not a fully informed refusal. This patient's decision fails to fill one of the basic requirements of adequately autonomous decision making. The question remains whether the autonomy of a marginally 
competent patient is of sufficient moral weight to require respect when a patient refuses life saving treatment. The prevalent Western opinion is yes: even marginal autonomy demands respect until it turns the corner of incompetence. The Israeli answer is different. Marginal competence, limited autonomy, and less-than-informed refusal fall before the duty to protect life.

Justifying this position calls for a clear understanding of the limits that patient autonomy and dignity impose on decision making. Marginal competence diminishes the value of autonomy so that forced treatment does not necessarily entail sufficient disrespect for a patient's autonomy to demand that we unquestionably honor his decisions. Forced treatment may, nonetheless, run afoul of respect for dignity, particularly as coercion entails restraint and/or sedation. The normative conflict, therefore, coalesces around life and dignity: respect for full autonomy is conspicuously absent when disagreements arise from disputed facts and competence is marginal.

When dignity stands alone, as it does when factual disagreements attenuate autonomy, it has a much harder time trumping life. In a society like Israel's, where respect for life supersedes respect for dignity, the decision is relatively unproblematic. However it may also be less problematic for those societies placing dignity ahead of life, like the United States, than is often thought. The indignity wrought by forced treatment is only one sort of indignity and does not entail a sweeping disrespect for dignity in general. Apart from being forcibly treated, the coerced patient is otherwise treated in a dignified manner by the medical staff, the healthcare bureaucracy, and by the state at large. Nevertheless, when dignity and full autonomy run together, as they sometimes do, their combined weight makes them difficult to override in favour of a patient's life or best interests. For this reason, a patient may not be coerced if his refusal stems from a disagreement of values. Israeli lawmakers missed this important point.

Informed refusals stemming from disputed values immediately invoke the protection that respect for autonomy provides. When refusals are informed, the decision to treat in defiance of a patient's wishes takes on different proportions and entails overriding dignity and respect for autonomy. Although some in Israel may think otherwise, I find it very difficult to overcome the combined weight of dignity and autonomy. One reason is an immediate sense that two principles outweigh one when the three are closely rankedhow closely ranked, however, remains contentious. Although most Israelis might agree on the ordinal rankings, their cardinal values may vary considerably. If the cardinal values are close, then two may outweigh one. If, on the other hand, life far outweighs the other two, as many in Orthodox religious circles, for example, believe, then the combined effects of autonomy and dignity may be insufficient to override an extended life span.

As it is written, the IPRA does not distinguish between disagreements of fact and value, and it tends to ignore the former. By demanding that caregivers ascertain informed consent before considering coercion, the law logically precludes disagreements of fact. We are not, by this provision, dealing with a patient who fails to understand the options before him, but with one who fully understands his condition yet, for reasons that are not clear to us, decides to refuse medical advice. If this is the intent of the law, it is wrongheaded. There are no good grounds to override a fully informed decision. Less-than-informed decisions are, however, an entirely different issue. Marginal competence necessarily raises the specter of forced choice, but it is not a sufficient condition: a marginally competent patient may be treated by force only when treatment promises "significant improvement".

\section{Condition 2: significant improvement}

Although factual disagreements generate the moral force to consider coerced treatment, there are firm grounds to demand that any treatment one means to impose by force yields significant, rather than simple or marginal, healthcare benefits. This proviso, central to Israel's law, means to offset the harm that comes with violating a patient's dignity through non-consensual treatment. The statute does not define the level of significance necessary to justify forced treatment but leaves it instead to the committee's discretion.

What criteria define "significant" benefit? The Israeli law, for example, demands that a patient face "grave danger" before a physician may consider treating a competent patient by force. In one regard this makes sense: one wants to prevent gross interventions unless a patient's very life is at risk. But "grave danger" — a broad term meaning simply that the disease will kill if left untreated-says nothing about the quality of life a patient may endure. This leaves the uncomfortable impression that one cannot treat a patient by force if the only purpose is to prevent extreme disability. Therefore, it seems logical to suggest that a significant change means a change from a lower level of functioning to a moderate or higher level of functioning regardless of life span. A longer life span alone regardless of the level of functioning makes little sense. Nevertheless, life span cannot be disregarded. Faced with conflicting aspects of beneficial care, the ethics committee must work toward a cogent definition of "significant improvement". One useful devise is quality adjusted life years (QALYs).

Quality adjusted life years, typically used to allocate scarce medical resources and measure the value of remaining life years following a medical procedure, are based on the product of two measures: the chance of success and the degree of success. The first indicates the probability that treatment will succeed in the limited sense of arresting the progress of a particular disease. The second is a measure of normal functioning that treatment will restore computed as the product of the quantity of life-that is, the number of life years following treatment and quality of life, a measure that takes into account distress and disability. The Rosser and Kind map of health states cited by Menzel is a typical example of these measures. ${ }^{11}$ Here post-treatment health states are evaluated relative to a patient's disability (on a scale of 1-8) and distress (on a scale of 1-4) (see table 1).

\begin{tabular}{|c|c|c|c|c|}
\hline \multirow[b]{3}{*}{ Disability } & \multicolumn{4}{|l|}{ Distress } \\
\hline & \multirow{2}{*}{$\frac{A}{\text { None }}$} & \multirow{2}{*}{$\frac{B}{\text { Mild }}$} & \multirow{2}{*}{$\frac{\mathrm{C}}{\text { Moderate }}$} & \multirow{2}{*}{$\frac{D}{\text { Severe }}$} \\
\hline & & & & \\
\hline 1. No disability & 1.000 & 0.995 & 0.990 & 0.967 \\
\hline 2. Slight disability & 0.990 & 0.986 & 0.973 & 0.932 \\
\hline $\begin{array}{l}\text { 3. Severe social disability or } \\
\text { slight impairment at work }\end{array}$ & 0.980 & 0.972 & 0.956 & 0.912 \\
\hline $\begin{array}{l}\text { 4. Choice of work severely } \\
\text { limited }\end{array}$ & 0.964 & 0.956 & 0.942 & 0.870 \\
\hline $\begin{array}{l}\text { 5. Unemployable but able to } \\
\text { perform a few simple tasks }\end{array}$ & 0.946 & 0.935 & 0.900 & 0.700 \\
\hline $\begin{array}{l}\text { 6. Confined to chair or } \\
\text { wheelchair }\end{array}$ & 0.875 & 0.845 & 0.680 & 0.000 \\
\hline 7. Confined to bed & 0.677 & 0.564 & 0.000 & -1.486 \\
\hline 8. Unconscious & -1.028 & - & - & - \\
\hline
\end{tabular}


Although disability states are fairly objective determinations, distress states are considerably more subjective and ranked using survey data culled from healthcare professionals and patients. Because forced treatment is not a global policy like resource allocation but focuses solely on the needs of a single patient, it is reasonable to turn to a patient's physician to elicit the level of distress a particular procedure may cause a patient. This, combined with the patient's disability state, gives a level of quality of life for the posttreatment years. A similar calculation yields an assessment of the pretreatment state. In each case one must also factor expected life span and the probability of proposed treatment achieving the intended result. One then compares a patient's pre- and post-treatment state of health to assess improvement.

Judging "significant" improvement, however, remains a difficult problem. Often overlooked by committee members for example, there is a crucial difference between "best interests" and "significant improvement". Consider the range of states indicated in table 1 . Intuitively there is a point of indifference where $\mathrm{x}$ years at $1 \mathrm{~A}=\mathrm{x}+\mathrm{n}$ years at a lesser state. A patient may decide, for example, that living for three years with slight disability is no more preferable to living for six years with moderate disability. Best interests lies just past this point, a relatively broad standard that only demands that the post-treatment state be marginally better (that is, have a greater score) than the pretreatment state. Thus any additional years of moderate disability would be in the best interest of the hypothetical patient just described. But best interest alone does not offset the harm done to a patient's dignity together with the stress that forced treatment causes medical personnel. These costs are difficult to quantify but are not trivial. They are only offset when treatment is, in some sense, significant and brings clear and overriding benefit. "Significant improvement", therefore, is much more narrowly defined than "best interests" and demands that the difference between the two treatment states be more than marginally better. Just how much better, however, remains a source of contention.

At present I can only suggest two ways to operationalise the idea of significant improvement. Firstly, one may undertake the same kind of research that generates maps of health states in the first place. This requires a large sample of medical staff and patients to assess the pretreatment and post-treatment states for various illnesses. Rating and scoring pre- and post-treatment states adjusted for remaining life years and then noting the difference that denotes "significance" yields a consensual coefficient of significant improvement. This may demand that the post-treatment state is $50 \%$ or $100 \%$ or $200 \%$ better than the pretreatment state. Whatever the coefficient, it is a measure that emerges from careful consideration of a number of cases by a diverse population.

In the absence of these data, ethics committee members must determine "significant improvement" themselves. Where this proves difficult they must ask themselves at least two pointed questions:

- Is it obvious (self evident) that treatment will significantly improve this person's life and not merely be in his best interest?

- Is it conceivable that a reasonable person could think otherwise?

Only by answering "yes" and "no" to questions 1 and 2 respectively is one reasonably assured about "significant improvement". If committee members have any doubt about the answer whatsoever then the criterion has not been satisfied. Framing the question in this way should make committee members realise that cases of legitimate forced treatment are relatively rare.

It is important to bear in mind that significant improvement, as a condition for forced treatment, is subordinate to informed consent. Only less-than-informed consent, brought on by factual disagreement, warrants forced treatment and only when the prospect of improvement is significant. Significant improvement alone is insufficient to justify forced treatment as a patient may take a deliberate and informed decision to refuse significantly beneficial treatment. Care that imposes certain financial or emotional costs on family members might be one example. These costs, which may be particularly important to a patient, interject an additional set of values and preferences into his decision making process. The disagreement hinges on values but is fully informed; it cannot be overridden merely because a patient refuses clearly beneficial care. Nor is there any reason to think, as the Israeli law seems to assume, that an informed patient will overturn his decision at a later date and provide consent retroactively.

\section{Condition 3: retroactive consent}

Retroactive consent, that is consent following treatment, is only intelligible in light of the distinction between disagreements of fact and value. In cases characterised by both true disagreements of fact and marginal competence, it is reasonable to assume that once the risks of non-treatment or the benefits of treatment become clear at a later date a patient will respond approvingly. This metamorphosis is, in fact, necessary, assuming that refusal to consent stems only from misinformation or lack of understanding. Once resolved, there is nothing to obstruct consent. It is equally conceivable that a marginally competent patient will never fully grasp his condition and never give consent. It is presumptuous, however, to expect that a competent patient's values would change fundamentally following medical treatment.

Nevertheless, one may wonder whether an acute illness may alter a patient's values so that following treatment one may agree to live in a fundamentally different way than one did before treatment. This is a difficult argument to assess. A patient may surely change his understanding of the risks and benefits, particularly if he initially miscalculated them. The healthcare professional sees this and treats the patient against his will because she knows that the risks and benefits are not what the patient thinks they are. The physician's assessment is objective and based on independently verifiable data. A patient may also change his values. He may become convinced that living without a leg or hooked up to a ventilator is not so bad after all. But then again he may not, and the healthcare professional has no way of knowing this in advance, nor are there sufficient grounds to make an educated guess.

The fact-value distinction reflects two distinct conceptions of a patient's good. The first is welfare; the second lies in the worth one attributes to the values and life goals one has chosen for oneself. Coercing a patient for his own good (welfare) may be justified, but compelling a patient to conform to a good (worthwhile values) one thinks one should hold is presumptuous. Isaiah Berlin draws out the distinction: "It is one thing to say that I may be coerced for my own good which I am too blind to see: this may, on occasion, be for my benefit; indeed it may enlarge the scope of my liberty. It is another thing to say that if it is my good, then I am not being coerced, for I have willed it, whether I know this or not, and am free even while my poor earthly body and foolish mind bitterly reject it, and struggle against those who seek however benevolently to impose it, with the greatest desperation." ${ }^{\prime 2}$ 


\section{THE LIMITS AND LESSONS OF ISRAEL'S PATIENT'S RIGHTS ACT}

The following two cases illustrate the limits and lessons of forcibly treating a competent patient.

\section{Case 1}

A 51 year old woman presents with severe urinary bleeding caused by a large tumour in her bladder. The preferred treatment is excision of the entire bladder (radical cystectomy) requiring a urine bag to collect and pass urine. In all likelihood her vagina will be removed as well thereby preventing normal sexual relations. The woman refuses surgery and she is discharged once her bleeding is stopped and condition stabilised. Her life is not in immediate danger. Her life expectancy without surgery could be a matter of several years occasioned by intermittent bleeding and hospitalisation until the tumour in her bladder causes more severe complications. Surgery, on the other hand, offers the prospect of a longer, pain free life.

This case presents some major difficulties for a healthcare system that allows forced treatment for it compels one to closely examine the idea of "significant improvement". Reacting to this case, some ethics committee members assumed immediately that the patient fulfilled the conditions for forced treatment: she is fully and competently informed, and her pretreatment state is superior to her post-treatment state following surgery. Upon closer inspection, however, this is not the case at all and the committee members who thought so were confused about several issues.

Firstly, they reasoned that any informed refusal was sufficient to invoke consideration of forced treatment, but this is incorrect. Only disagreements of fact, not disputed values, offer firm moral grounds for coercing a patient to accept treatment. In case 1 , the patient refuses treatment to avoid a disadvantageous health state characterised by lack of normal sexual functioning. Committee members, for their part, found it difficult to comprehend that she did not understand that her postoperative handicaps were offset by the prospect of a much longer life. For committee members, the value of a longer life was paramount. Regardless of the merits of their claim, they should have recognised immediately that her refusal stemmed from disputed values and could not, therefore, trigger non-consensual treatment. Failing to understand the moral limits of the law, the committee proceeded to examine the second condition of forced treatment, namely significant improvement. Here, too, they erred for they immediately confused significant improvement with best interests.

In the case above, the woman may have one, two, or three years of near normal functioning (1A in table 1). Her postoperative state is, at worse, $5 \mathrm{D}(0.700)$ and perhaps higher. One would also have to multiply this coefficient times the likelihood the operation will succeed. If the surgery has only a 90\% success rate, her postoperative state drops accordingly. At one point, weighing the years she will live at 1 A may balance additional years at 5D. She may fully grasp her condition and reason that no number of years at 5D outweighs the years she will get at 1A or, more likely, she will conclude that the number of $5 \mathrm{D}$ years is insufficient to overcome the fewer number of years at 1A. Were she not fully competent, one may call upon the assessment of an impartial spectator. This observer must, however, avoid a mere best interest argument. Best interests come into play just after the point where $x$ years of $1 \mathrm{~A}$ balance $\mathrm{x}+\mathrm{n}$ years of $5 \mathrm{D}$. But this is not "significant improvement". Without an objective measure of "significant improvement" as suggested above, then the observer, like members of the committee, must ask whether it is self evident that this person's life will be significantly improved by treatment and whether it is conceivable that a reasonable person could think otherwise. In this case, it is doubtful that our impartial spectator will answer yes and no to these two questions respectively and fulfill the second condition for forced treatment. This is not the situation in case 2 .

\section{Case 2}

A 65 year old man enters the hospital for routine hernia surgery but following complications requires artificial ventilation. The patient pulls at his tubes resists the ventilator vigorously making it difficult to wean him. After three weeks the team decides that a tracheostomy will make the patient more comfortable and greatly increase the chances of successfully weaning the patient from the ventilator and leading a near normal life. However, it is difficult to communicate with the patient. Although a psychiatric assessment confirms that he understands his condition and is aware that he might die without intervention, the patient seems distracted by discomfort and dismisses his doctors with a wave of the hand when they suggest a tracheostomy. Without the tracheostomy the medical team sees little chance of successfully weaning the patient from the ventilator.

In contrast to opinion prevalent in many Western nations, this case obligates forced treatment. It is a misplaced notion of autonomy that demands, as one American bioethicist suggested to me privately, that the patient in case 2 be set up with a morphine drip, offered privacy, and allowed to die with dignity if he no longer wants the vent and understands he will die without it. Forced intervention is permissible in this case because the post-treatment state is superior to the pretreatment state. Committee members were convinced that this was self evident, beyond mere best interests and inconceivable that a reasonable person could think otherwise. But forced treatment is only permissible because the dispute between the patient and physician is anchored in facts not values. The patient has not rejected his post-treatment state because he his revolted by the quality of life it presents (as in case 1), but because he is marginally competent. He has shown no ability to recount, explain, and defend his decision nor does he seem to fully understand the implications of nontreatment. Concern for the patient's life and the chance for significant improvement override respect for the patient's limited autonomy.

\section{CONCLUDING REMARKS}

At its best, the Israeli Patient's Rights Act allows physicians to face the dilemma of less-than-informed refusal. This is a difficult quandary. Given the harsh realities health care presents for patients in an acute setting informed consent is not always easy to secure. Ordinarily, we pay little attention to less-than-informed consent, particularly as patients usually decide and behave as we wish them to. Yet this does not mean we should be equally indifferent about less-thaninformed refusal. Competent patients making mistakes pose difficult problems for it means acting distastefully when it is easier to accede to a patient's refusal under the guise of "respect for autonomy".

Marginal autonomy does not offer the same compelling grounds for respect as full autonomy. Suspecting that a patient does not fully comprehend the situation he faces, a responsible physician may double her efforts to explain the facts only to find that her patient still refuses life saving treatment. Forcibly treating a marginally competent patient-that is, one whose refusal stems from disputed facts rather than values does not mean violating autonomy as much as it marks a refusal to surrender to ignorance. It is a difficult decision making process for healthcare professionals, but ethics committees of the kind established by Israel's Patient's Rights Act may help ease the process through a 
deliberative forum and thereby serve as a model for similar forums in other nations.

Once the conditions for marginal competence and significant improvement are satisfied, there is a moral obligation to treat patients against their will, and no grounds for respecting a patient's less-than-informed refusal. Marginally competent patients are not unique to Israel and the dilemma they pose for ethicists, together with the lessons gleaned from the Israeli case, should engage healthcare professionals wary that respect for autonomy may sometimes cause avoidable harm.

\section{REFERENCES}

1 Israel Patient's Rights Act, 1996. English translation available at http:// waml.haifa.ac.il/index/reference/legislation/israel/israel 1.htm (accessed 2 August 2004).
2 Gross ML. Autonomy and paternalism in communitarian society: "patients' rights in Israel". Hastings Cent Rep 1999;29:13-20.

3 Mason JK, McCall Smith RA. Law and Medical Ethics, 5th edition. ButterworthHeinemann, London, 1999:244-88.

4 Engelhardt HT Jr. The Foundations of Bioethics, 2nd edition. Oxford: Oxford University Press, 1996:303-26.

5 Rahamim Gibli $v$ the State of Israel, 829/96-A.

6 White BC. Competence to Consent. Georgetown: Georgetown University Press, 1994, 154, 183.

7 Thewes J, Fitzgerald D, Sulmasy DP. Informed consent in emergency medicine: ethics under fire. Emerg Med Clin North Am 1996;14: 245-54

8 Cassell EC, Leon AC, Kaufman SG. Preliminary evidence of impaired thinking in sick patients. Ann Intern Med 2001;134:1120-3.

9 Moskop JC. Informed consent in the emergency department. Emerg Med Clin North Am 1999; 17:327-40.

10 Glick SM. The morality of coercion. J Med Ethics 2000;5:393-5.

11 Menzel PT. Strong medicine: the ethical rationing of healthcCare. Oxford: Oxford University Press, 1990

12 Berlin I. Two concepts of liberty. In Four Essays on Liberty. Oxford: Oxford University Press, 1969:134. 